\title{
Sizing and dynamic modelling and simulation of a standalone PV based DC microgrid with battery storage system for a remote community in Nigeria
}

\author{
Cherechi Ndukwe \\ Memorial University, St. John’s, Newfoundland, Canada, E-mail: cindukwe@mun.ca \\ Tariq Iqbal \\ Memorial University, St. John's, Newfoundland, Canada, E-mail: tariq@ mun.ca
}

Arrived: 26.03.2019 Accepted: 31.05.019 Published: 30.06.2019 Check for

\begin{abstract}
In this paper, a solar PV powered DC microgrid is proposed and designed for Umuokpo Amumara in Nigeria with 800 households and a number of community installations which include churches, schools, shops, and a water pumping system. The appropriate sizes of system components are determined to meet the all-time load demand. A Techno-economic feasibility study was carried out in Homer Pro to determine the energy needs of the community and as well the system size and configuration that best suits the community. The energy requirement of the community was obtained to be $3.16 \mathrm{MWh}$ /day. The battery storage system was also sized in this work and a battery system capacity of $21,944 \mathrm{Ah}$ was able to meet the community energy requirement for up to a day without renewable energy supply. The dynamic model of proposed the microgrid was simulated in MATLAB/SIMULINK to observe the system's dynamic response in view of the power quality, load impact, and battery storage charging. The results obtained from the simulation depicted a stand-alone DC microgrid that is capable of meeting the daily electrical energy requirements of the system with good voltage stability. The PV system used in the system could function at maximum power conditions even with variation in the weather conditions. This was achieved by employing the Incremental Conductance MPPT system.
\end{abstract}

Keywords: $\quad$ DC microgrid, HOMER Pro, Dynamic modeling and simulation, Solar PV, Renewable energy

Cite this paper as:

Ndukwe, C., Iqbal, T. Sizing and dynamic modelling and simulation of a standalone PVbased DC microgrid with battery storage system for a remote community in Nigeria, Journal of Energy Systems 3(2);(2019); 67-85, DOI: 10.30521/jes.544710

(C) 2019 Published by peer-reviewed open access scientific journal, JES at DergiPark (www.dergipark.gov.tr/jes)

Nomenclature

AC $\quad$ Alternating Current

ADPMS Adaptive Dynamic Power Management Strategy

DC Direct Current

MPPT Maximum Power Point Tracking

NPC Net Present Cost

PV Photo-Voltaic 


\section{INTRODUCTION}

Most rural areas in Nigeria have been with no electrical supply from the national grid. This is mainly attributed to lack of access to these areas, which therefore transcends to the high cost of grid installations. Worldwide, there is an estimation of above 1.5 billion people who lack access to electricity [1]. These communities have therefore resorted to the use of local methods to meet their lighting, heating, and cooking needs. This, in turn, has a detrimental effect on their economic stabilities. Most times, these areas have abundant renewable energy resources such as; wind, solar, and hydro that are sources of cheap and clean energy. It is, therefore, recommended that these sources of energy be explored to provide electricity for these rural areas.

Microgrids can be of two types, which are the AC microgrid and the DC microgrid. For this community, a DC microgrid was proposed with the following reasons as; easy integration with renewable energy sources and storage [1,2], availability of most DC loads [3,4], loss reduction due to lower number of conversion stages [5], low cost of distribution and low system complexity [6].

Due to the absence of grid in Umuokpo Amumara since its existence and the very high availability of solar energy resource that can be harnessed for isolated microgrid, a Solar PV based DC microgrid will be an efficient way to generate stable and cheap electricity for the community.

This paper focuses on the sizing and dynamic modeling of a standalone solar PV based DC microgrid for electrification of Umuokpo Amumara. To the best of the authors' knowledge, a DC microgrid has never been proposed in existing literature for this geographical area. Therefore, this can be considered novel for the geographical area. Specifically, the contributions of this paper include:

Development of a DC microgrid to provide power to the rural settlement. Feasibility study of the proposed DC microgrid to meet the electrical needs of the community. Dynamic modeling and simulation of the proposed DC microgrid including Maximum Power Point Tracking and DC Voltage Control.

\section{LITERATURE REVIEW}

DC microgrid is an attractive technology in modern electrical grid system because of its natural interfacing with the existing renewable energy sources [2]. The DC microgrid system is made up of mostly renewable energy sources and delivers the energy to the components of the microgrid in Direct current form. Here the components of the microgrid are connected directly to the sources through the system bus and as a result, there is no need for conversion of the power. Figure 1 shows the block diagram and architecture of a DC microgrid. 


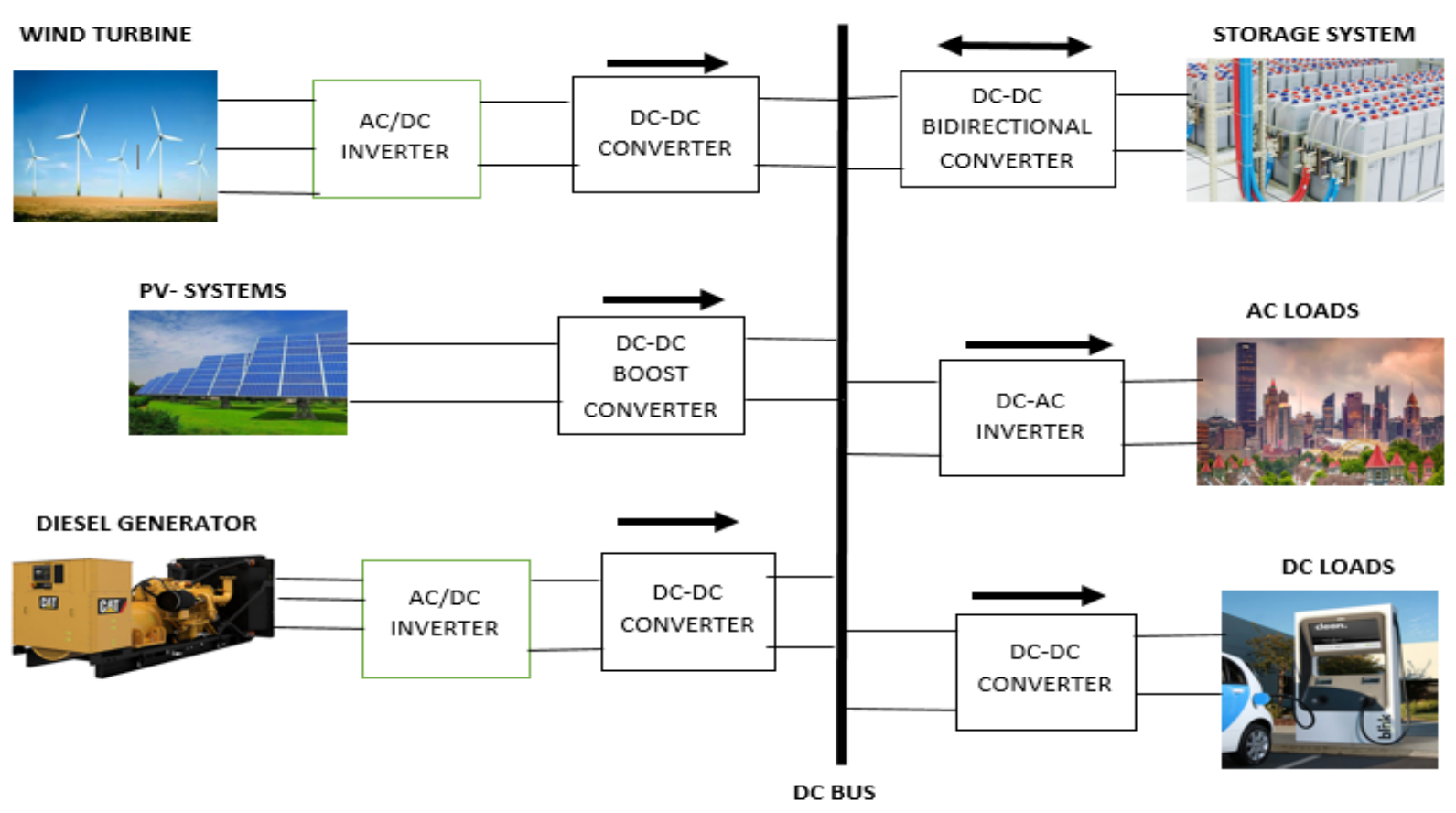

Figure 1. Schematic Diagram of a Stand-alone DC microgrid

A DC microgrid conventionally consists of the Renewable Energy Source, the DC bus, the storage system and the loads, which may be either AC or DC. As earlier mentioned the main advantage of the DC microgrid is the elimination of the high number of power conversion stages that lead to many losses. A PV-Wind energy based DC microgrid, which incorporates a battery bank for storage, was proposed in [7]. The paper stated the importance of an optimal mix of renewable resources and storage to obtain a balanced system. Also, the system saw the incorporation of DC-AC converters to feed the AC loads in the telecommunication system. NSGA II optimization technique was employed for the sizing of the system. Cost of energy generation and high reliability were the justifications given by [8] for the shift in paradigm from the conventional AC energy generation to DC generation. The paper stated its focus as the rural area considering the low accessibility to electricity. The paper also stated that the orientation of the rural settlement has a very large effect on the configuration of the system, which in turn affects the efficiency of the system. Linear and clustered arrangements are the two forms of arrangements that are normally aligned with the rural settlements. The work employed NewtonRaphson's method modified for DC power flow to analyze the overall system losses. A DC microgrid was designed in [9], and the system did not employ the usual battery stack for energy storage but instead employed a variation of super-capacitors assisted regulators uninterrupted power supply. This energy bank has the advantage of fast transient time and low noise during its operation. Light dimming and air conditioning control systems were incorporated into the design to achieve optimal energy usage and low electricity consumption. The design of a DC microgrid for a residential building was carried out in [10]. This design was carried out for a microgrid with two DC voltage levels 380VDC and 24 VDC. The higher voltage was to feed the high power appliances in the building such as the refrigerators and dryers while the lower voltage value is for the low power devices. From simulations in SIMULINK AND PSIM, the design was validated and a conclusion reached that the 380/24VDC microgrid is more economical than the AC counterpart. A self-reliant DC microgrid was sized and experimented in [11]. The paper presented the sources of energy as PV photovoltaic system and fuel cells. Super-capacitors and electrolyzer systems were combined in the system as hybrid storage. The Adaptive Dynamic Power Management Strategy (ADPMS) is employed in the sizing to solve the normal impediments of DC microgrids which include; variation in sources and load, fuel starvation phenomenon of the fuel cell and the state of Charge $(\mathrm{SoC})$ of the super-capacitor. The study was validated using a laboratory scale DC microgrid test bed. DC microgrids have been known overtime for high efficiency and reliability while having no frequency and reactive power issues [12]. Various operational controls have been studied by different researchers on the system and some of these 
control systems include; centralized control [13], master-slave control [14], multi-agent control [15], distributed autonomous control [16]. From most research results, it is observed that the distributed control system is mostly used due to its advantage of more autonomous and flexible control configuration.

\section{SYSTEM SIZING}

In power generation and distribution, the accurate supply of power to customers is paramount. Thus the need for a power system that meets the energy requirement of the consumers. This research entails the design and simulation of a DC microgrid that will supply power to 800 houses in a remote part of the eastern region of Nigeria. This section of the research will depict the details of;

Accurate measurement of the load profile of the community.

A study of the available renewable energy resources in the community.

Optimal sizing of the power system.

Community Load Profile.

\section{Daily Profile}

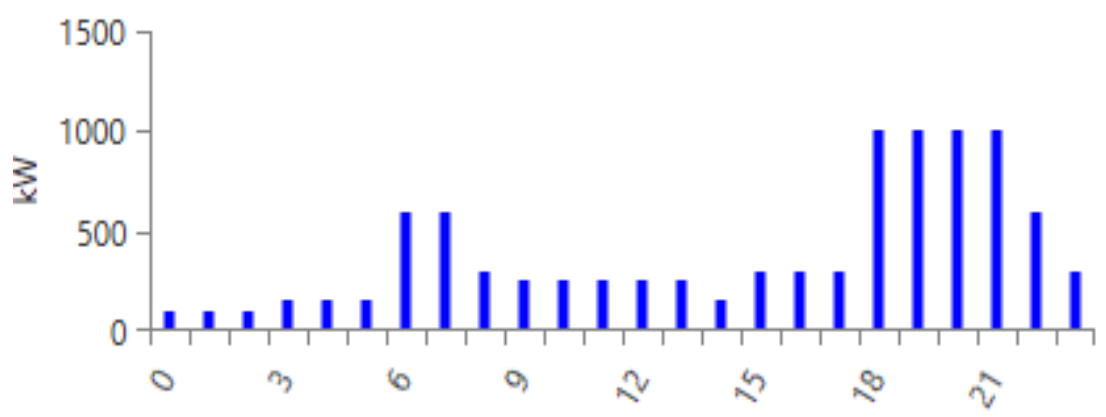

Figure 2. Umuokpo Daily Load Profile

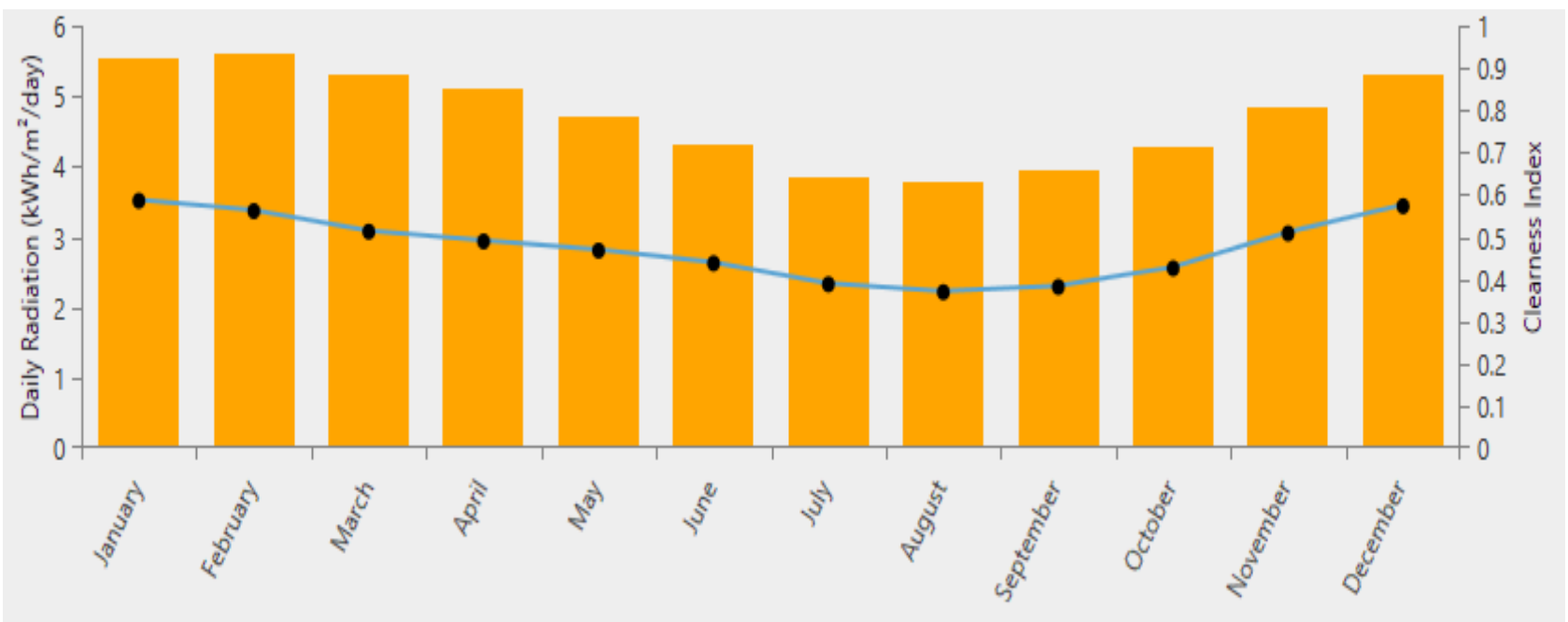

Figure 3. The Plot of solar irradiation 
The village consists of about 8,000 inhabitants with 800 houses and some community centers such as the schools, churches, and town hall. The village is a working-class village where inhabitants have various jobs and leave the house in the morning to return in the evenings. Nigeria has just two seasons in the year, which are the rainy and dry seasons. Figures 2 and 3 show the community daily load profile and the solar irradiation respectively. The installations and basic electrical needs of the community are shown in Tables 1,2 , and 3.

Table 1. Installations in the Project Site

\begin{tabular}{ll}
\hline \multicolumn{1}{c}{ Installations } & Number in Village \\
\hline Houses & 800 \\
Schools & 2 \\
Churches & 3 \\
Town hall & 1 \\
Small Shops & 20 \\
Village Water Pumping System & 1 \\
\hline
\end{tabular}

Table 2. DC Electrical load of Each House

\begin{tabular}{ccccc}
\hline Installation & DC Electrical features & Load rating $(\mathrm{W})$ & Hours of operation & Energy (Wh/day) \\
\hline 4 bedrooms & $4 * 8.5 \mathrm{~W}$ bulbs & 34 & 6 & 204 \\
Sitting room & $2 * 8.5 \mathrm{~W}$ bulbs & 17 & 6 & 102 \\
Kitchen & $8.5 \mathrm{~W}$ bulb & 8.5 & 6 & 51 \\
Bathroom & $8.5 \mathrm{~W}$ & 8.5 & 6 & 51 \\
Balcony & $14 \mathrm{~W}$ & 14 & 6 & 84 \\
Television & $30 \mathrm{~W}$ & 30 & 10 & 300 \\
Stereo & $20 \mathrm{~W}$ & 20 & 4 & 80 \\
Ceiling Fan & $15 \mathrm{~W}$ & 15 & 5 & 75 \\
Refrigerator & $150 \mathrm{~W}$ & 150 & 20 & 3000 \\
\hline Total & & 297 & 3,947 \\
\hline
\end{tabular}

Table 3. DC Electrical load for Public Installations

\begin{tabular}{lcccc}
\hline \multicolumn{1}{c}{ Installation } & Electrical features & $\begin{array}{c}\text { Load } \\
\text { rating(W) }\end{array}$ & $\begin{array}{c}\text { Hours of } \\
\text { operation }\end{array}$ & $\begin{array}{c}\text { Energy } \\
(\text { Wh/day })\end{array}$ \\
\hline Schools (2) & $2 *(10 * 8.5 \mathrm{~W}$ bulbs $)+$ & 187 & 6 & 1122 \\
Churches (3) & $(2 * 8.5 \mathrm{Wbulbs})$ & 255 & 4 & 1020 \\
Town hall & $3 *(10 * 8.5 \mathrm{~W}$ bulbs $)$ & 34 & 3 & 102 \\
Small shops (20) & $4 * 8.5 \mathrm{~W}$ bulbs & 170 & 12 & 2040 \\
Village water Pumping system & $20 * 8.5 \mathrm{~W}$ bulbs & 1000 & 2 & 6,284 \\
$(1)$ & $1000 \mathrm{~W}$ & 1,646 & & 2000 \\
\hline Total & & & \\
\hline
\end{tabular}

From Table 2, it is observed that each house has a peak load of $0.30 \mathbf{k W}$, which amounts to $238 \mathbf{k W}$ when the 800 houses are considered. In addition to the houses, the village also has some public installations. The total peak load of the village is a sum of the power from all the house appliances and the public installations. This is calculated as shown below:

$$
\text { House Peak + Community Peak= Global Village Consumption }
$$


Heating and cooking are not included in the load profile as the village employs traditional methods for heating and cooking. In a conventional Nigerian home, the peak usage of power occurs in the evenings from 16.00-22.00 as the community is at full capacity during this period. As a result, power usage will be low in the morning and afternoon hours. The village has a total energy consumption of $3.16 \mathrm{MWh} /$ day. The village has an average solar irradiation of $4.7 \mathrm{kWh} / \mathrm{m}^{2} / \mathrm{d}$, which depicts the possibility of good energy from the solar resources available in the area.

\subsection{Battery Sizing}

The storage system is very important in a microgrid. This system is employed to store excess energy generated by the generation system and then supplies the microgrid in days of low production. The battery capacity is obtained by: (here $\mathrm{E}_{\text {day }}$ is the energy need of the community for a day).

$$
\begin{aligned}
& E_{\text {total }}=\frac{E_{\text {day }}}{\text { Inverter eff. }} \\
& E_{\text {total }}=\frac{3160 \mathrm{kWh}}{0.95}
\end{aligned}
$$

The battery capacity is calculated as:

$$
\begin{gathered}
\text { Batt Cap }=\frac{E_{\text {total }} \times \text { Autonomy Days }}{\text { Bus Voltage } \times \text { Batt EFF } \times \% D O D} \\
=\frac{3160000 \times 1}{360 \times 0.8 \times 0.5} \\
=21,944 \mathrm{Ah}
\end{gathered}
$$

Therefore, number of batteries in series:

$$
\begin{gathered}
N_{S}=\frac{\text { Bus Voltage }}{\text { Battery Nominal Voltage }} \\
=\frac{360}{12} \\
=30 \text { batteries }
\end{gathered}
$$

Number of batteries in Parallel:

$$
\begin{aligned}
N_{p}= & \frac{\text { Total Battery Size }}{\text { Rating of Battery }} \\
=\frac{21944}{140} & 156 \text { batteries in parallel }
\end{aligned}
$$

\section{HOMER SIZING RESULTS}

The simulations to pick the most feasible system for the village electrification was carried out in HOMER software. From the simulation, the most feasible system was selected based on the Net Present Cost (NPC) analysis, which highlights the system that meets the load demand at the lowest reasonable cost. 
The optimal system consists of a 1,000kW PV array, a 630kW Diesel generator as backup and 4,680 units of battery system for energy storage. The PV is the main source of energy, while the generator and battery system are used to meet energy needs when the PV system is lower than the demand.

The optimal system achieved $88.6 \%$ renewable energy fraction with electrical production of $1.38 \mathrm{GWh} / \mathrm{yr}$ from the PV array. The generator also, which is used as back up is ON only for just 616 hours in the whole year. This amounts to about 1.6 hours daily. The battery system is charged with the excess electricity produced during the PV operational hours. During the nights when the PV systems cannot produce power, the battery feeds the grid with stored power as can be observed in Figure 4. The battery system has a nominal capacity of $7,857 \mathrm{kWh}$ with an autonomy time of 29.8 hours.

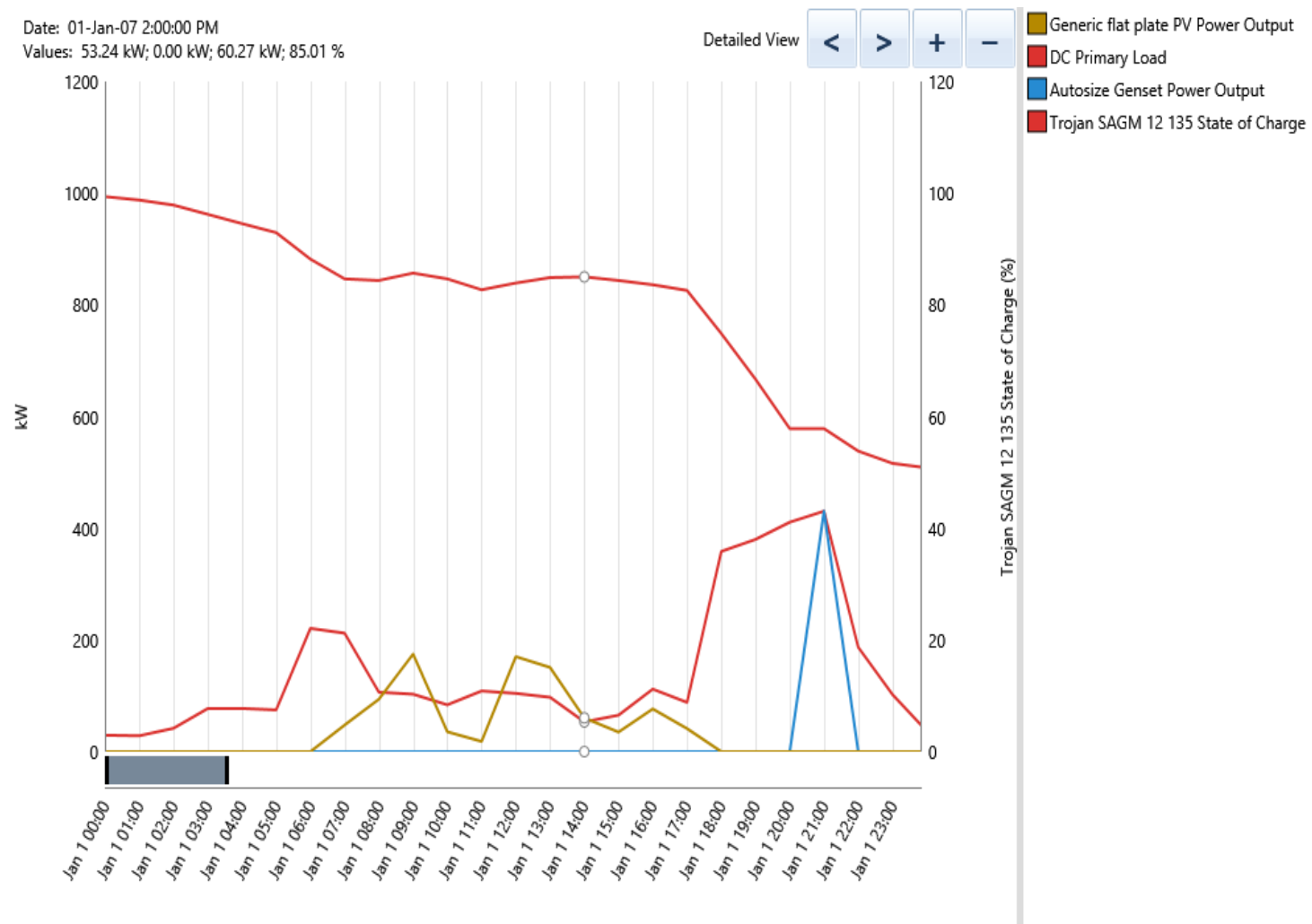

Figure 4. Plot of daily Electrical component activities

From the sizing, the PV system comfortably meets the load power requirements and therefore makes the generator system strictly for back up. Also, the system depicts that the excess energy is applied to the charging of the battery system and thus the low value of excess energy to $15 \%$ of the generated energy. The low value of the excess energy depicts a very balanced electrical system.

\section{SYSTEM OVERVIEW AND DESCRIPTION}

The Proposed DC Microgrid power system consists of the following:

A PV array for trapping energy from the sun.

A battery storage system to supply needed power in days of low renewable resources

Boost converter

Buck converter 
The aim of the proposed system is to supply and satisfy the electrical requirement of the Umuokpo community with a high penetration of the renewable energy source and the battery storage system. Considering that a standard has not been specified for the DC voltage levels, a 360V DC bus voltage for the power distribution in the system was employed. This choice was made after thorough studies which indicated much usage of the 360VDC as it is ideal for long community distance distribution and also suites the high amount of power that will be distributed through the community while meeting the safety level required as well. The system employed 24VLDC in-house distribution line, which is safe for residential usage and a 48VLDC for the community water pumping system.

The block diagram of the proposed DC microgrid is shown in figure 5.

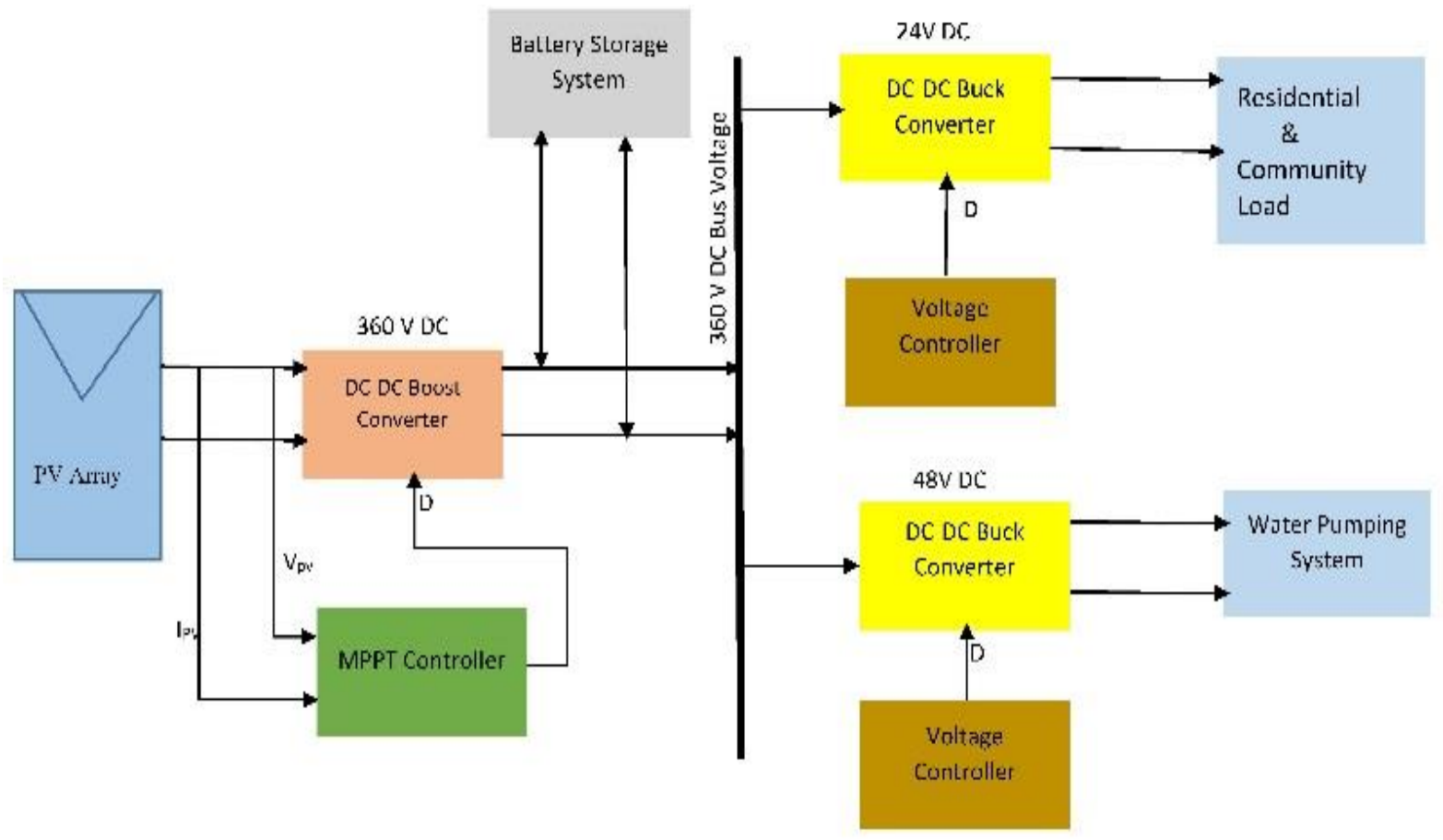

Figure 5. Block Diagram of the proposed DC microgrid

\subsection{Solar PV Model}

The sample model of the PV module comprises of a photocurrent source, a diode and some internal resistance connected as shown in Fig 6.

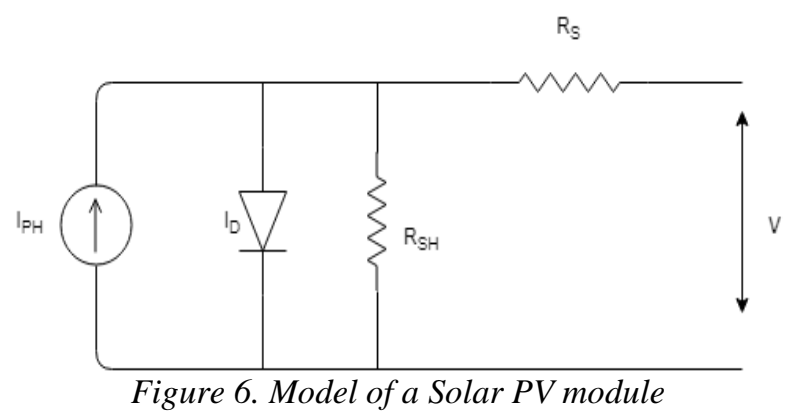

The current obtained from the PV module is given by:

$$
I=I_{P H}-I_{D}=I_{P H}-I_{O}\left(\exp \left[\frac{e\left(V+I R_{S}\right)}{K T_{C}}\right]-1\right)-\frac{V+I R_{S}}{R_{S H}}
$$


Also, for low internal power dissipation, it is important to note that shunt or parallel resistors will be of larger value than the load resistance [2] which therefore can lead to the negligence of the two resistances to obtain the current (I) as the difference between the photocurrent $\left(\mathrm{I}_{\mathrm{PH}}\right)$ and the diode current $\mathrm{I}_{\mathrm{D}}$ as shown in equation 2.

$$
I=I_{P H}-I_{D}=I_{P H}-I_{O}\left(\exp \left[\frac{e V}{K T_{O}}\right]-1\right)
$$

Where: $\mathrm{k}=$ Boltzman Constant, $\mathrm{T}_{\mathrm{c}}=$ Absolute Cell Temperature, $\mathrm{e}=$ electronic charge, $\mathrm{V}=$ Voltage across cell, $\mathrm{I}_{\mathrm{O}}=$ Dark saturation current.

The fixed PV array has a minimum array size of $6.84 \mathrm{~kW}$. This PV array consists of 416 modules per string connected in series and 8 strings in parallel, resulting in 24 modules per array. Each $300 \mathrm{~W}$ solar panel contains $72 \mathrm{PV}$ cells connected in series. The parameters of the solar module employed in this study are shown in table 4.

Table 4. PV Module Electrical Specification

\begin{tabular}{ll}
\hline Electrical Specification & Value \\
\hline Cells Per Module & 72 \\
Module Efficiency & $15.21 \%$ \\
Power Output Tolerance & $0 /+3 \%$ \\
Maximum Power Voltage & $37.5 \mathrm{~V}$ \\
Maximum Power Current & $8.00 \mathrm{~A}$ \\
Open Circuit Voltage - V $\mathrm{oc}_{\mathrm{oc}}$ & $46 \mathrm{~V}$ \\
Short Circuit Current & $8.44 \mathrm{~A}$ \\
Peak Power Watts - Pmax & $300 \mathrm{~W}$ \\
\hline
\end{tabular}

The $I-V$ curve and P-V curves of the BOSH ENERGY c-Si M72 NA41126 300Wp panel under 400, 600, 800, and $1000 \mathrm{~W} / \mathrm{m}^{2}$ solar radiation are presented in Fig. 7.
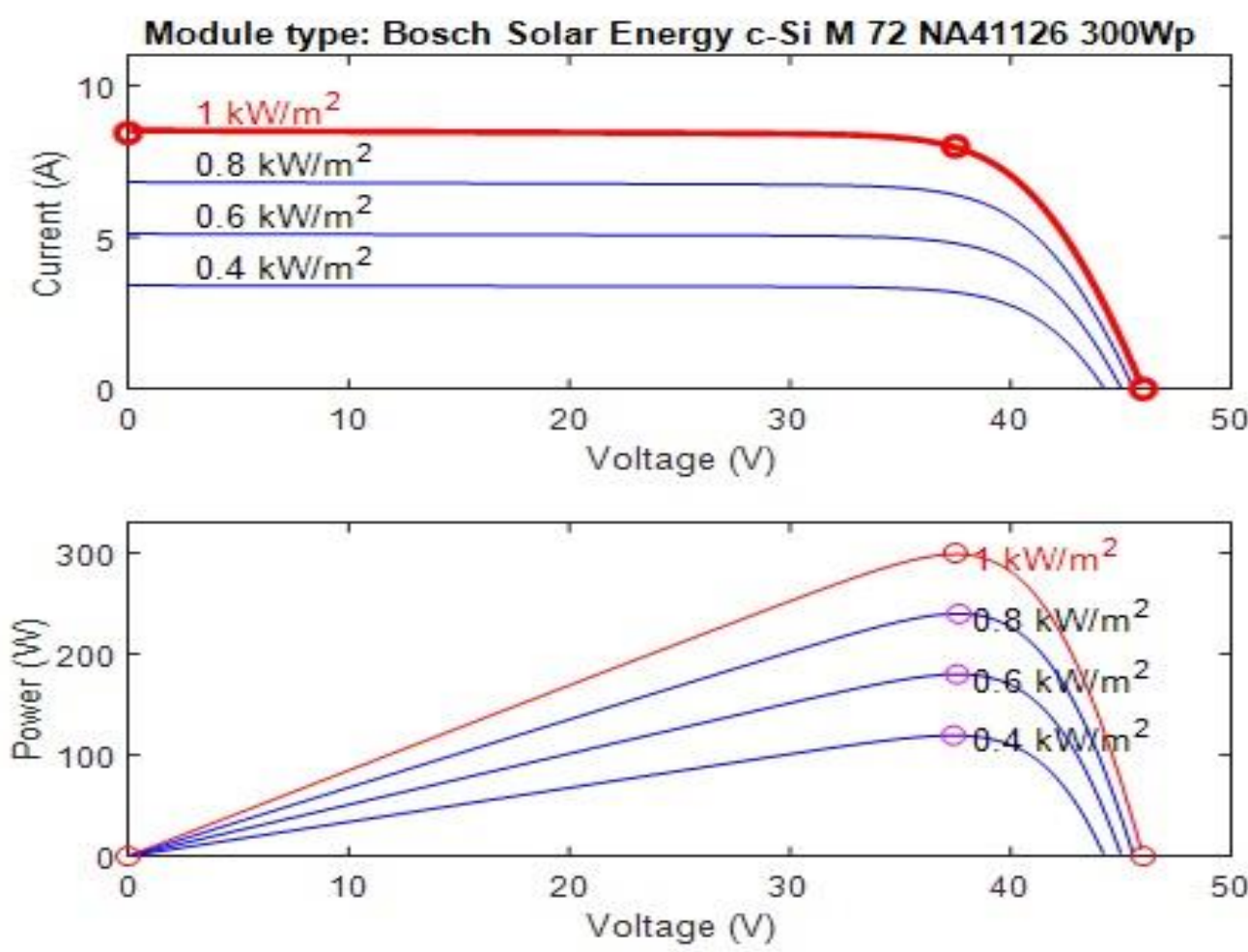

Figure 7. I-V and PV curve of the $300 W$ PV module 


\subsection{Battery Storage Design}

The rate of discharge, depth of discharge, and temperature are the main factors that determine the life span and capacity of a battery storage system. In this paper, the Lead-Acid battery system is employed due to its simplicity and availability in the African market. Also, the Lead-Acid battery is more temperature tolerant and as a result, will function well in the hot temperature in Africa. Generally, in microgrids, battery systems are normally employed to supply energy needs to the loads at times of low energy generation from renewable energy sources. The battery storage system is also employed to smoothen voltage variations which occur as a result of the intermittent nature of the renewable energy sources. The specifications for the battery storage system are tabulated in table 5 .

Table 5. DC microgrid Battery Storage Parameters

\begin{tabular}{ll}
\hline Electrical Specification & Value \\
\hline Nominal Voltage (V) & $360 \mathrm{~V}$ \\
Rated Capacity (Ah) & $21,944 \mathrm{Ah}$ \\
Maximum Capacity (Ah) & $22,858.3 \mathrm{Ah}$ \\
Initial state of Charge (\%) & $70 \%$ \\
Cut off Voltage (V) & $270 \mathrm{~V}$ \\
Capacity at Nominal Voltage (Ah) & $6,808.7 \mathrm{Ah}$ \\
\hline
\end{tabular}

\subsection{DC-DC Boost Converter}

The DC-DC boost converter has the function of stabilization and steps up (boost) of the unregulated voltage that is obtained from the PV system. In this microgrid, the DC-DC boost converter steps up the PV voltage to the $360 \mathrm{~V}$ bus voltage as needed for transmission and also to charge the battery system. The equivalent circuit diagram of the boost converter is shown in Figure. 8. As observed from the circuit diagram, the output voltage and current of the converter can be obtained from equations (3) and (4) respectively [ref]. From the stated mathematical expressions, it can be vividly observed that the converter output is affected by the duty cycle, D and also the input. As a result, by variation of the duty cycle with the input being fixed, the output can be controlled.

$$
V_{O}=\frac{1}{1-D} \times V_{i}
$$

$$
I_{O}=\frac{1}{1-D} \times I_{i}
$$

Where: $\mathrm{D}=$ Converter duty Cycle, $\mathrm{V}_{\mathrm{o}}=$ Output Voltage, $\mathrm{V}_{\mathrm{i}}=$ Input Voltage, $\mathrm{I}_{\mathrm{o}}$ and $\mathrm{I}_{\mathrm{i}}=$ Currents

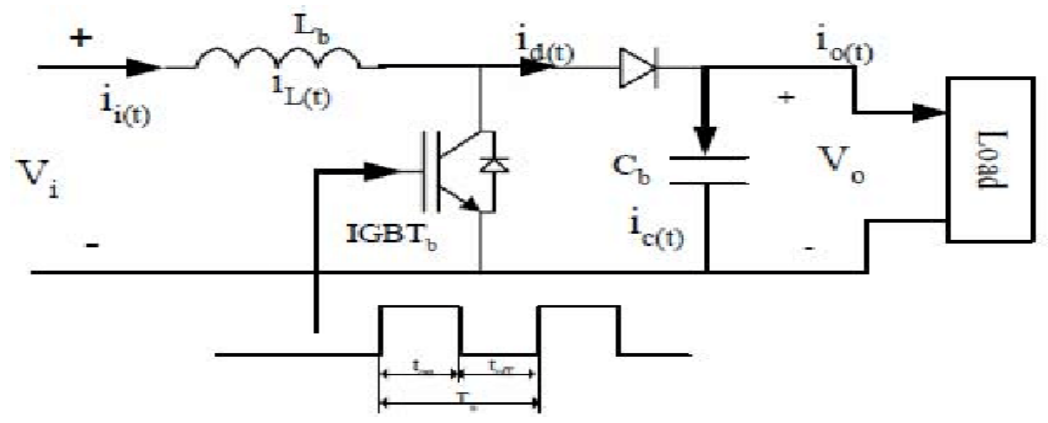

Figure 8. DC-DC Boost Converter Circuit Diagram

\subsection{DC-DC Buck Converter}


The DC microgrid had different levels of voltage required for use at the load end, such as the residential buildings and the water pumping system. The DC-DC buck converter was employed to step down the voltage from the bus voltage to low voltages of $24 \mathrm{VDC}$ and 48VDC which are then fed to the homes and water pumping system respectively. The circuit diagram for the buck converter is shown in figure. 9.

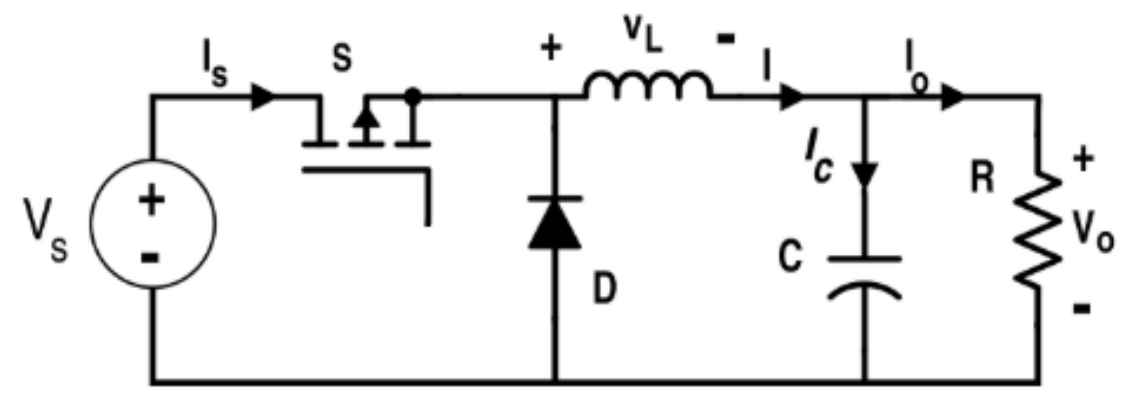

Figure 9. DC-DC Buck converter

The output voltage of the DC-DC buck converter can be obtained using equations (5). Also, the buck converter is known to increase the current while stepping down the voltage.

$$
V_{O}=D \times V_{i}
$$

Where: $\mathrm{D}=$ Converter duty Cycle, $\mathrm{V}_{\mathrm{o}}=$ Output Voltage, $\mathrm{V}_{\mathrm{i}}=$ Input Voltage.

\subsection{MPPT Controller}

The PV system works as shown on the I-V characteristics at every point an Operating Point (OP) which is highly dependent on the existing irradiance and temperature and this, in turn, affects the amount of power that can be extracted from the PV module. This, therefore, means that without any external control, the PV module will produce power only with direct effect from the variation in irradiance and temperature. Hence the intermittent nature of the power produced. Given the need to maintain maximum operating point at all time without effect from varying geographical conditions, an external system which is capable of tracking the various maximum points in the I-V characteristic curve will have to be employed. This system is defined as the Maximum Power Tracking System. Maximum Power Tracking can be achieved using various algorithms. In this paper, the Incremental Conductance MPPT algorithm is employed sequel to its efficiency and high level of accuracy of the usual Perturb and Observe algorithm [17]. The algorithm makes use of the voltage and current from the PV array as input to generate pulses which in turn are used to control DC-DC Boost converter duty cycle D. The Incremental Conductance algorithm is not affected by the solar module characteristics. This algorithm is illustrated by equations (6) and (7) and also shown in figure 10. The flowchart of the incremental Conductance MPPT algorithm is shown in figure 11. 


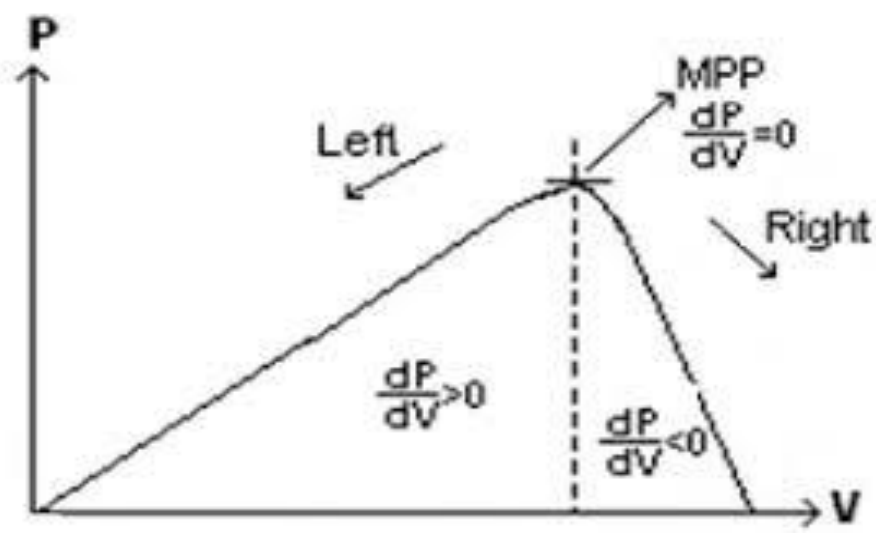

Figure 10. Incremental Conductance MPPT

$$
\begin{gathered}
P=V \times I \\
\frac{d P}{d V}=\frac{d(V \times I)}{d V}=V \times \frac{d I}{d V}+I
\end{gathered}
$$

Where: $\mathrm{P}=$ Power, $\mathrm{V}=$ Voltage, $\mathrm{I}=$ Current, $\mathrm{dI} / \mathrm{dV}=$ Conductance. At MPPT, $\mathrm{dI} / \mathrm{dV}$ or $\mathrm{dP} / \mathrm{dV}$ must be equal to zero (0).

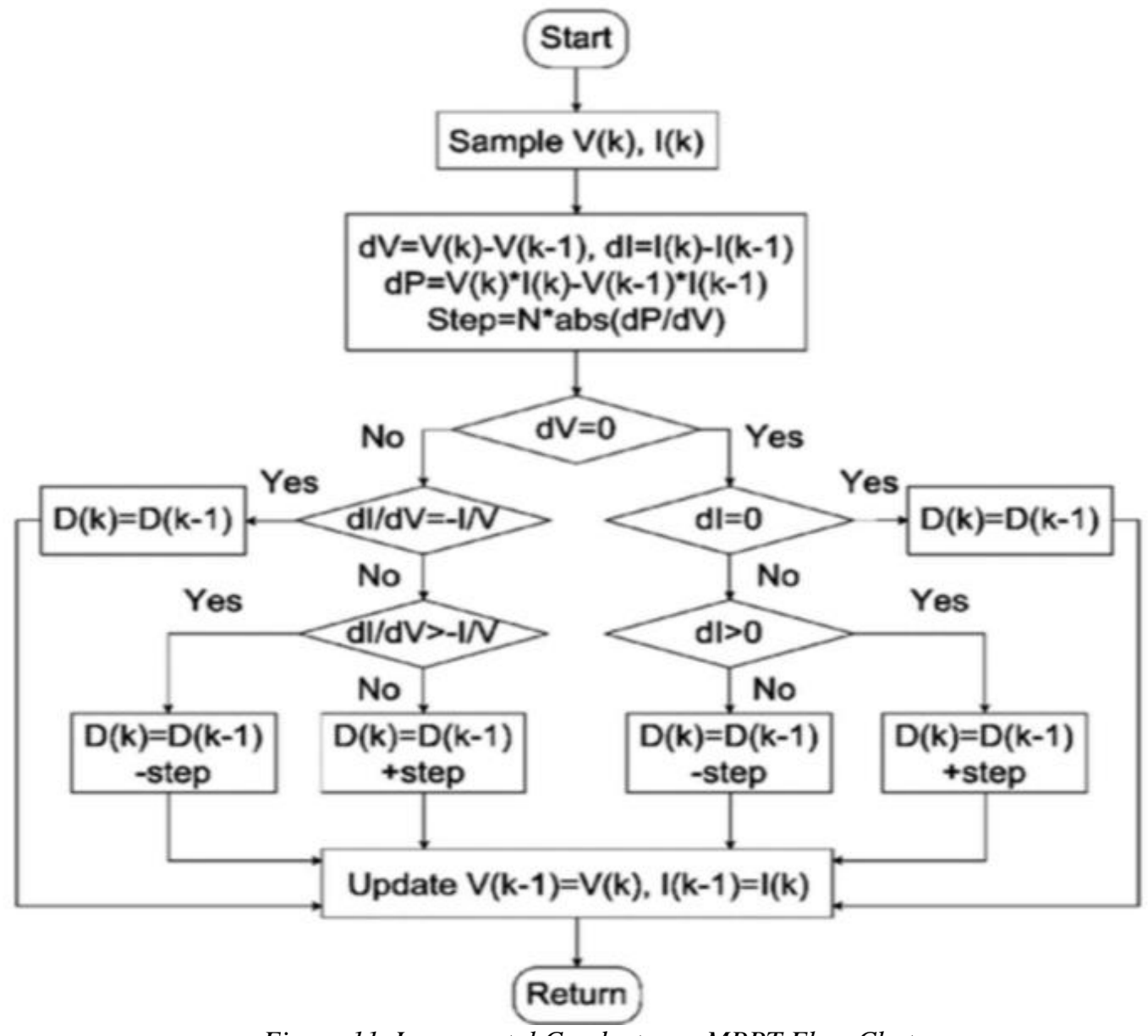

Figure 11. Incremental Conductance MPPT Flow Chat

\subsection{Voltage Mode Controller}


The buck converter output voltage can be quite easily affected by variations from the system parameters [18]. Hence, the need for a control system which is capable of maintaining constant voltage notwithstanding any system distortion. In this paper, the voltage mode controller was applied to the proposed system. This is due to the robustness of the system and its ease of application [18]. The voltage mode controller is, as shown in figure 12. Here, the DC voltage from the Boost Converter is detected and compared with the set references voltage. Any observed error is sent back to the PI controller as feedback with is applied to produce a voltage, which is constant and very close to the ref voltage. The voltage controller carries out this function continuously, to keep the DC voltage maintained.

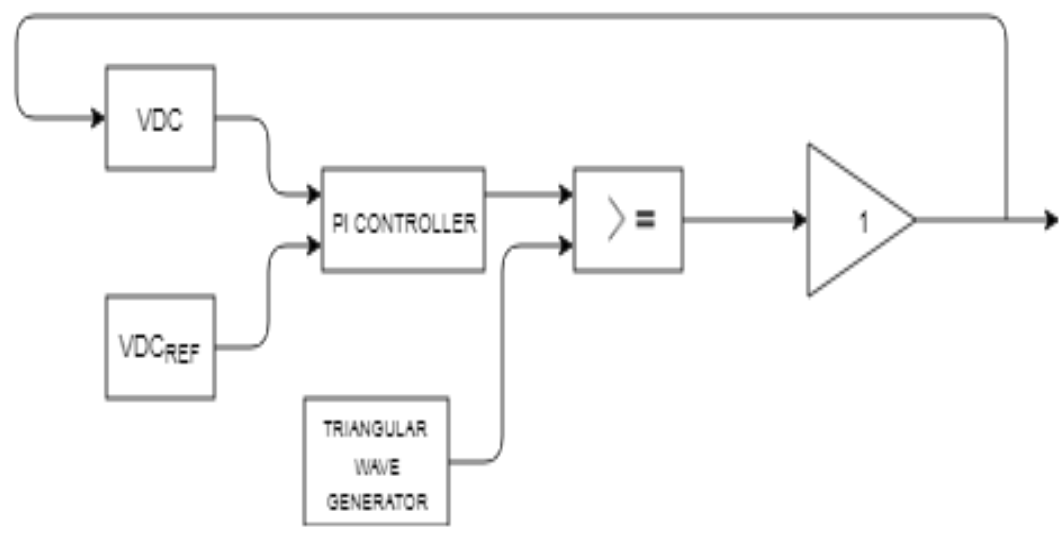

Figure 12. The Voltage Control Block

\section{DYNAMIC SIMULATION OF THE PROPOSED DC MICROGRID ON SIMULINK}

Dynamic simulation is a very important step in the design and optimization of any system. For power systems, the dynamic simulation is carried out to observe the instantaneous and timely behavior of the system under study. This is to observe the dynamic behavior of the proposed system given the power quality, voltage stability, and load variation effects. The proposed DC microgrid was simulated in MATLAB/SIMULINK under various geographic and electrical conditions which are particular to the Umuokpo community. Parameters for the simulation were also obtained from the various datasheets of the selected components. Due to the high number of homes in the community, it will not be very feasible to simulate 800 houses on the software. Therefore, for clarity, all houses were assumed to have the same power requirements. 3 houses were simulated on SIMULINK and the water pumping system, which was operating on a different voltage level was also modeled in a different branch. The rest of the community load was also simulated on another branch. The loads were represented in SIMULINK with resistor values that correspond to the power requirement of each load, and hence the current behavior was also observed. Although the last branch had a very large amount of current, it was included for simulation purposes only, but will be separated accordingly during physical development.The overall MATLAB/SIMULINK model of the DC microgrid is shown in Figure 13. 


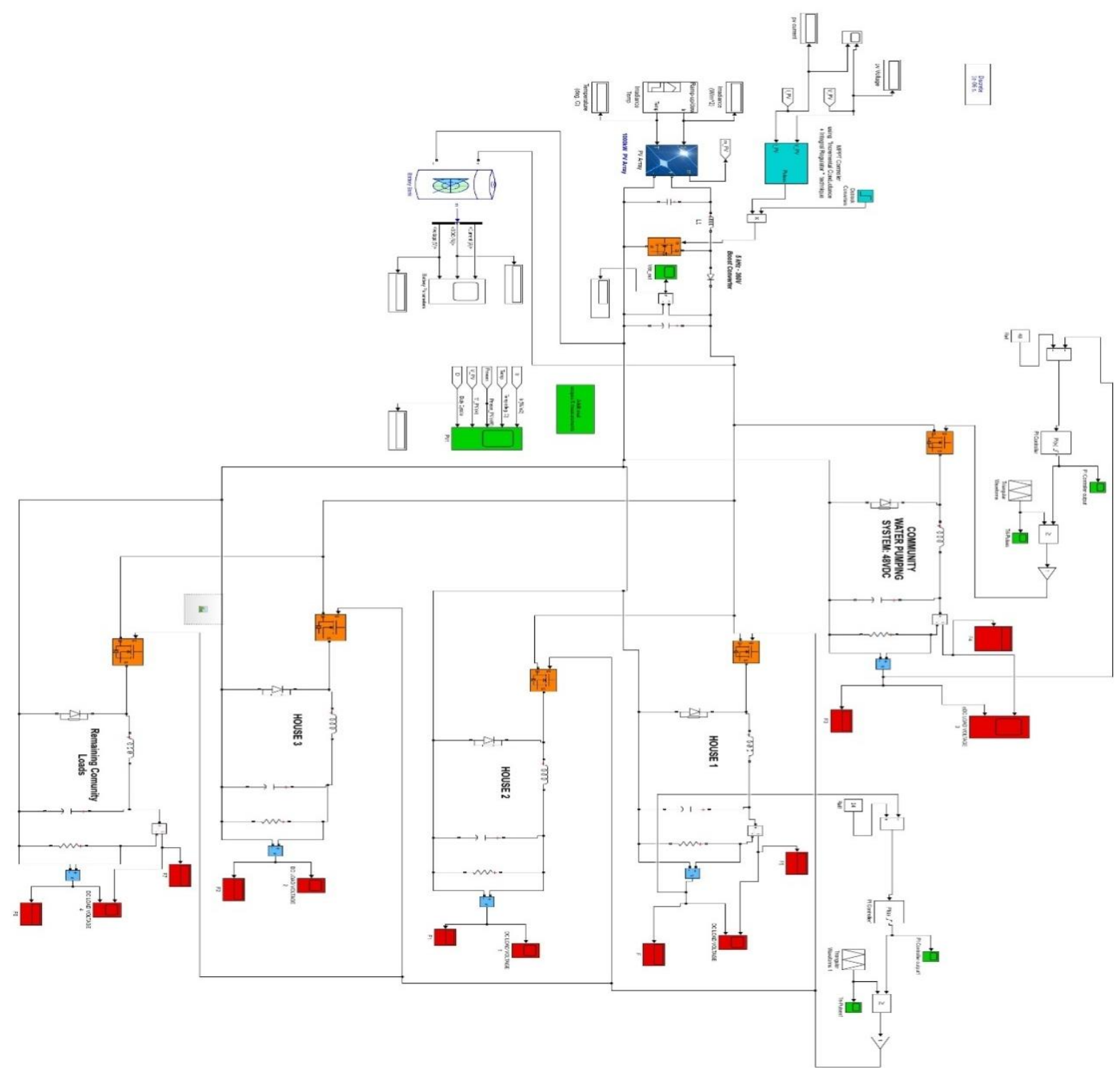

Figure 13. MATLAB/SIMULINK model of the Proposed DC microgrid

\subsection{Dynamic Simulation Results}

The overall Simulink model of the proposed DC microgrid was simulated on MATLAB/SIMULINK for 1 minute, and the following important results were observed as shown from Figures. 14-18. 

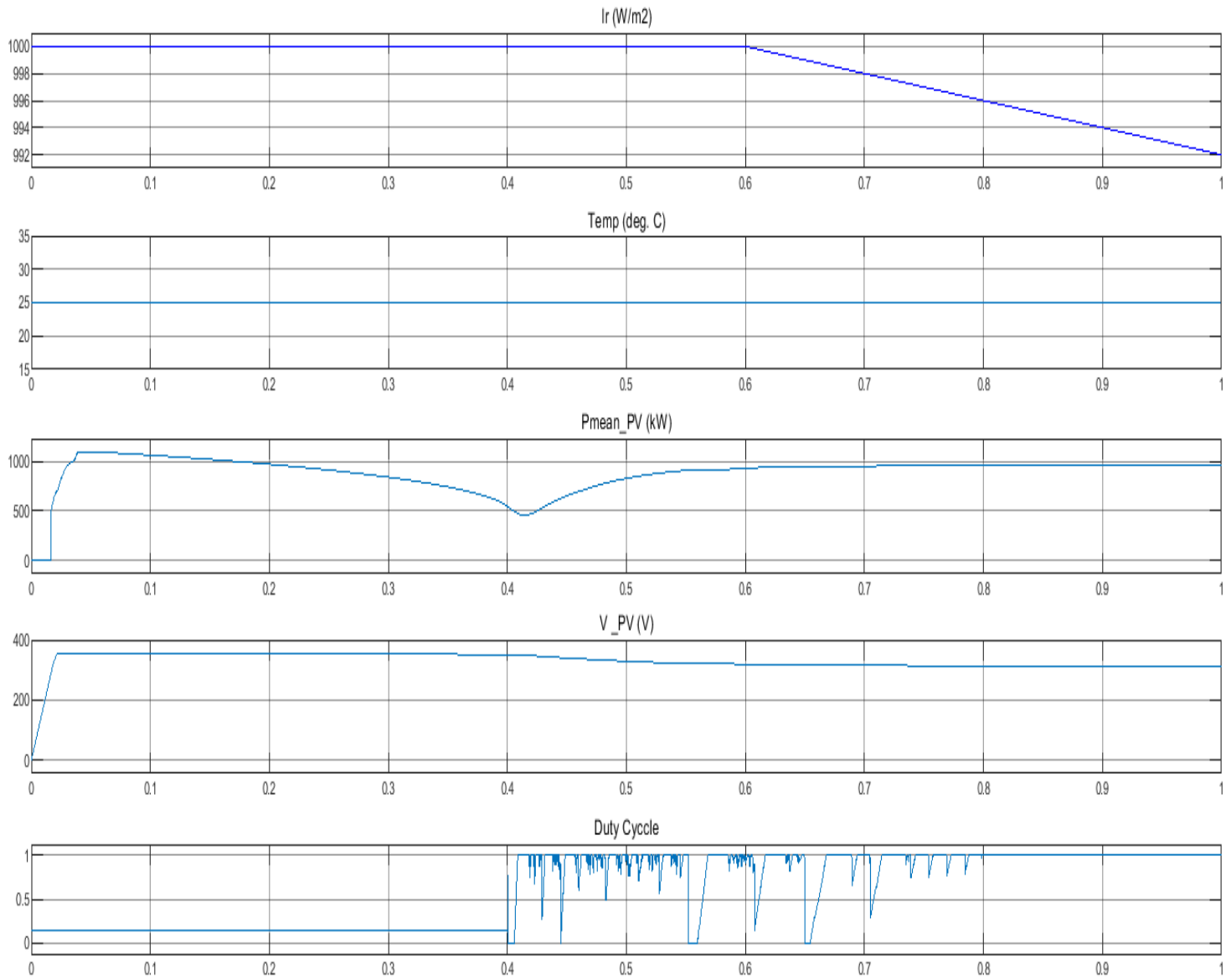

Figure 14. Solar Irradiance, Temperature, Generated Power

Figure 14 shows the solar irradiance and temperature at which the PV system is being operated. Also, the figure displays the PV generated power, which shows its value as very close to the power of $1000 \mathrm{~kW}$. The figure also depicts the continuous production of maximum power even with a decrease in the irradiance conditions, and this can be seen from the duty cycle plot with fluctuations. These fluctuations show that the MPPT control works continuously to keep power production at the maximum point. Figure 15 displays the DC-DC boost converter output voltage. It illustrates that the output voltage from the PV system is boosted to the system proposed 360VDC bus voltage.

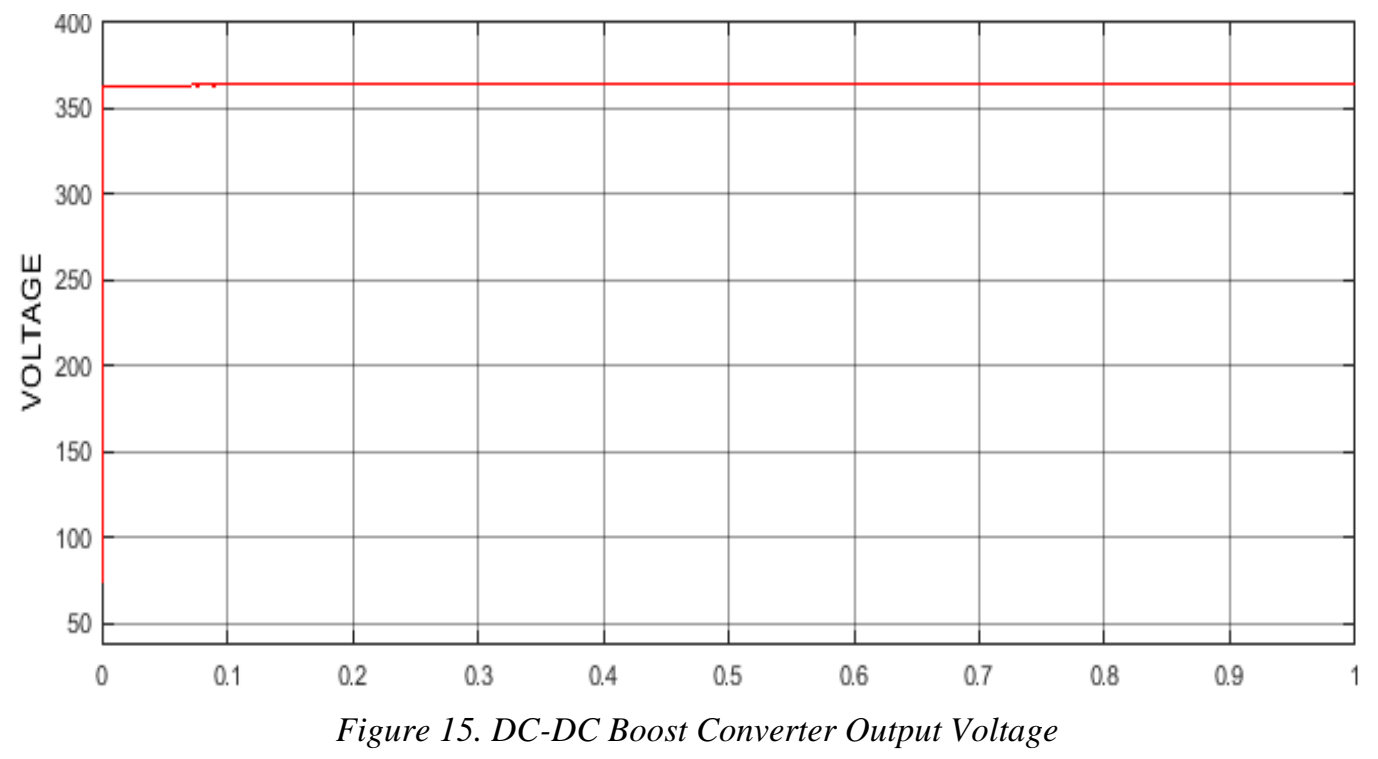



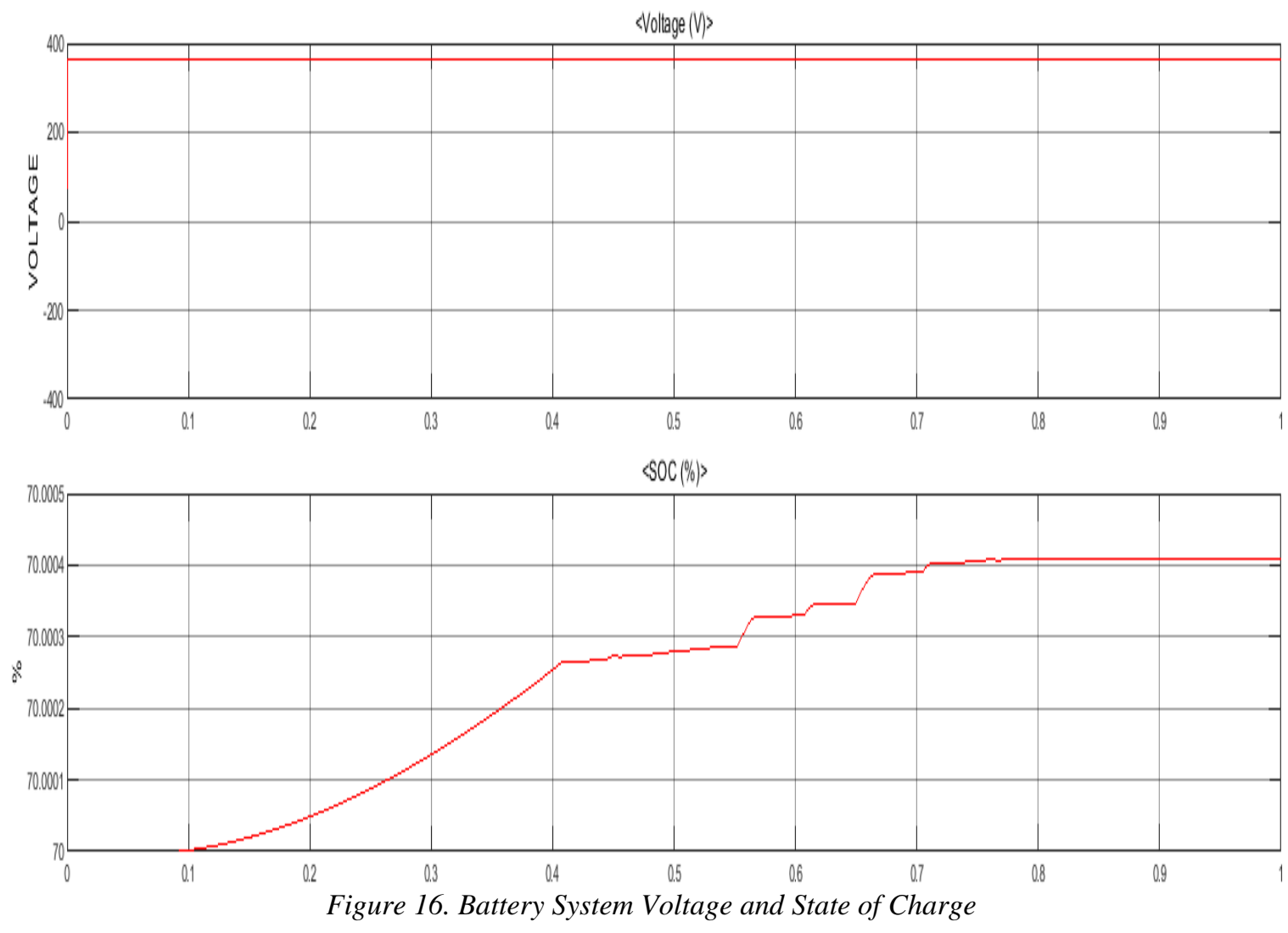

Figure 16 describes the battery storage system voltage, which is shown as $360 \mathrm{~V}$. This means that the battery system can supply power to the system with the system bus voltage. Also, the state of Charge of the battery system is shown in the figure as it increases from an initial state of charge of $70 \%$ as stipulated in the simulation. This increase in the state of charge shows that the battery system is also being charged during the PV operation during the period of good irradiance.

Two load plots have been displayed in this work, as shown in figures. 17 and 18. Figure 17 depicts the load as connected to one residential home with voltage stepped down to $24 \mathrm{~V}$ by the buck converter for domestic use. Also, the current was shown as displayed. The $24 \mathrm{~V}$ was proposed for domestic use to accommodate even some high voltage devices in the home. Figure 18 shows the display of the community water pumping system, which had its voltage stepped down to 48VDC to satisfy the voltage requirement of the chosen water pumping device. The current was also shown in the display. 

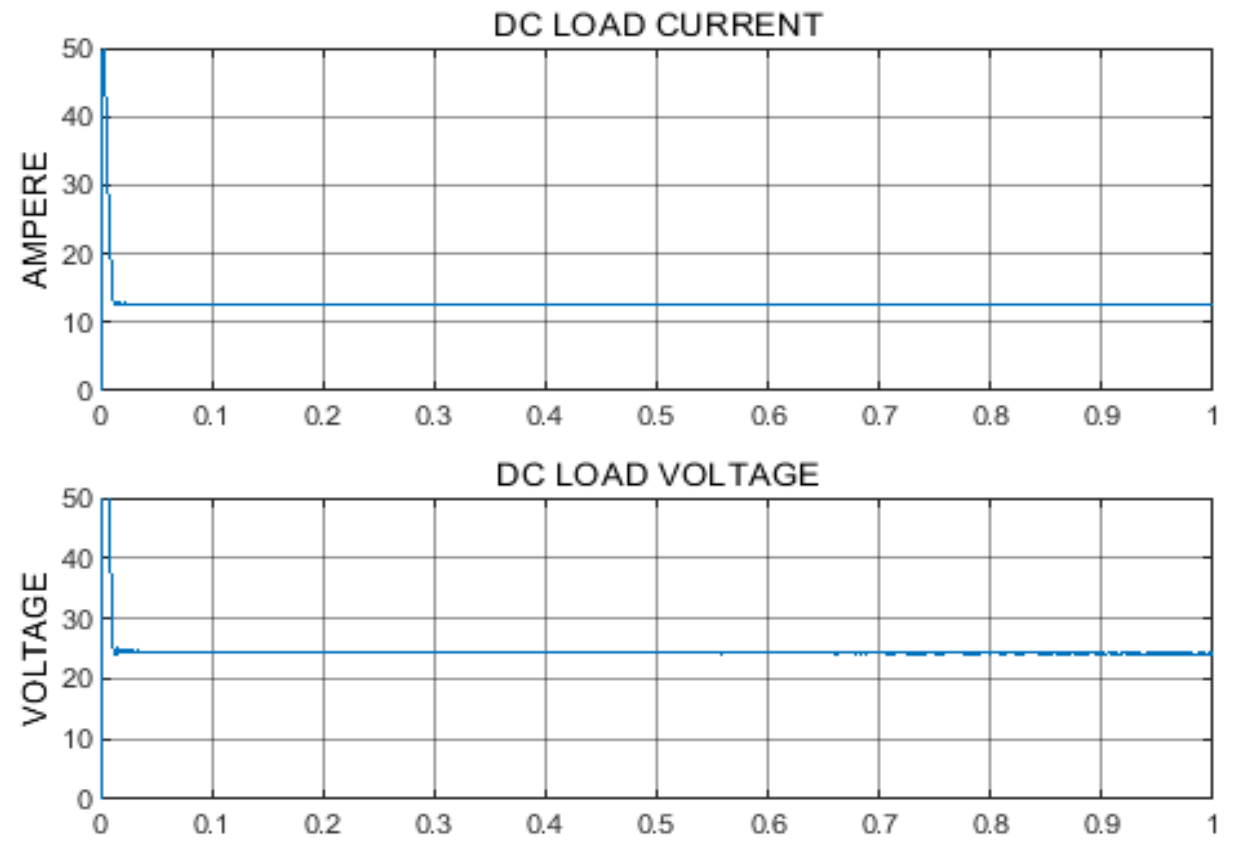

Figure 17. Voltage and Current output for Residential house

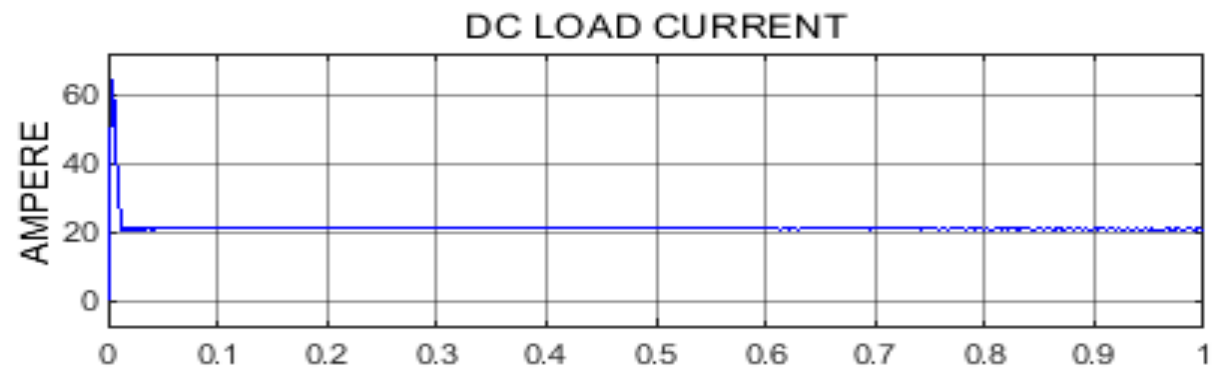

DC LOAD VOLTAGE

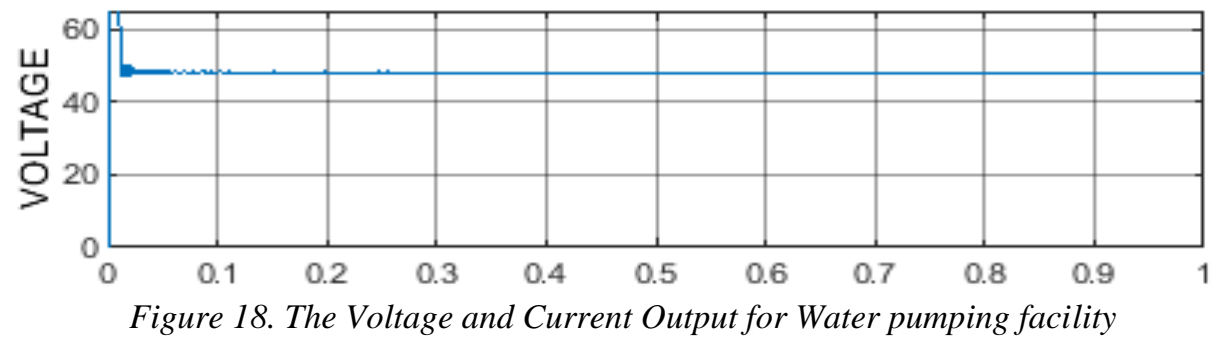

From all voltage displays, it will be observed that the voltages were of constant value, which depicts the proper functioning of the voltage mode controller to keep the load voltages at the desired voltage levels irrespective of any impact from the loads.

\section{CONLUSIONS}

This paper carried out the optimal modeling of a DC microgrid for Umuokpo Amumara, a remote community in Eastern Nigeria following the absence of grid electricity in the area since its existence. 
The optimal techno-economic modeling simulated on HOMER Pro, taking into account the size of the community, location, and the different facilities that exist in the community that require electrical energy as these parameters are of importance when proposing a power system for a specified location. Having known the energy requirements of the community $(3.16 \mathrm{MWh} /$ day $)$, the optimal power system that can meet the energy requirements of the community was obtained from HOMER Pro. To achieve this, the daily load profile of the community, solar and wind resource availability, the various components needed for the project such as the PV, wind turbine, and battery system were into HOMER. In Homer, various simulations were run; to carry out the techno-economic feasibility of the system and this took into account factors such as the system size and configuration, availability of the renewable energy resources and some economic factors such as life cycle of the system, net present cost, maintenance cost and annual operating cost for the system. The optimum system as proposed by the Homer simulation comprises of the PV, diesel generator that is strictly for backup and a battery storage system. To observe the near real-life behavior of the system for transient reactions, the optimal system obtained from HOMER was simulated in MATLAB/SIMULINK. In the simulation, the power quality, voltage stability, and load impact were observed. The outputs obtained from the simulation such as the constant voltage, the maximum power operation and charging of the battery system depicted a very functional and feasibly independent power system that is capable of standing as a solution to the long period the community has existed without electricity as it can comfortably meet its energy requirements. In future, a comparison of the existing storage system which is Lead-acid battery and a storage system based on Ultra-capacitors can be carried out to observe the difference in behavior and know which storage system is more suitable for the DC microgrid. Furthermore, a test-bed experiment will be carried out to observe the physical behavior of the systems for real-life testing.

\section{REFERENCES}

[1] Shaver L. Implementation of a DC Microgrid. Master's Degree, University of Wisconsin-Madison, USA, 2017.

[2] Elsayed A, Mohamed A, Mohammed O. DC microgrids and distribution systems: An overview. Electric Power Systems Research 2015; 119: 407-417.

[3] Ryu S, Ahn J, Cho K, Lee B. Single-Switch ZVZCS Quasi-Resonant CLL Isolated DC-DC Converter for 32" LCD TV. Journal of Electrical Engineering and Technology 2015; 10(4): 1646-1654.

[4] Thomas B. Edison revisited: impact of DC distribution on the cost of LED lighting and distribution generation. In: 27th Annual IEEE Applied Power Electronics Conference and Exposition (APEC); 2010: 588-593.

[5] Vijayaragavan K. Feasibility of DC Microgrids for Rural Electrification. Master's Degree, European Solar Engineering School, Sweden, 2017.

[6] Kumar D, Zare F, Ghosh A. DC Microgrid Technology: System Architectures, AC Grid Interfaces, Grounding Schemes, Power Quality, Communication Networks, Applications, and Standardizations Aspects. IEEE Access 2017; 5: 12230-12256.

[7] Kaur R, Krishnasamy V, Kandasamy N. Optimal sizing of wind-PV-based DC microgrid for telecom power supply in remote areas. IET Renewable Power Generation 2018; 12(7): 859-866.

[8] Hamza M, Shehroz M, Fazal S, Nasir M, Khan H. Design and analysis of solar PV based low-power lowvoltage DC microgrid architectures for rural electrification. In:IEEE Power \& Energy Society General Meeting, Chicago, USA, 2017.

[9] De Zoysa H, Guruge P, Kalingamudali S, Kularatna N, Kanishka G. Designing and constructing a DC microgrid with uninterrupted power supply capability and optimizing its energy usage by smart controlling system. In: IEEE International Conference on Industrial Electronics for Sustainable Energy Systems (IESES), New Zealand, 2018.

[10] Webb V. Design of a 380 V/24 V DC Micro-Grid for Residential DC Distribution. Master's Degree, The University of Toledo, Spain, 2013.

[11] Ramesh Naidu B, Panda G. Siano P. A Self-Reliant DC microgrid: Sizing, Control, Adaptive Dynamic Power Management and Experimental Analysis. IEEE Transactions on Industrial Informatics 2018; 14(8): 3300-3313. 
[12] Shuai Z, Fang J, Ning F, Shen Z. Hierarchical structure and bus voltage control of DC microgrid. Renewable and Sustainable Energy Reviews 2018; 82: 3670-3682.

[13] Zhou T, Francois B. Energy management and power control of a hybrid active wind generator for distributed power generation and grid integration. IEEE Transactions on Industrial Electronics 2011;58(1):95-104.

[14] Panov Y, Rajagopalan J, Lee FC. Analysis and design of N paralleled DC-DC converters with master-slave current-sharing control. In: Proceedings of APEC 97 -Applied Power Electronics Conference, Atlanta, GA, 436-442, 1997.

[15] Li C, Vasquez JC, Guerrero JM. Multiagent-based distributed control for operation cost minimization of droop controlled DC microgrid using incremental cost consensus. In: Proceedings of the 41st Annual Conference of the IEEE Industrial Electronics Society, IECON 2015, Yokohama, 5202-5205, 2015.

[16] Zhang GG, Li C, Qi D, Xin H. Distributed estimation and secondary control of autonomous microgrid. IEEE Transactions on Power Systems 2017;32(2):989-998

[17] Peake S. Renewable Energy: power for sustainable future, 4th edition, Oxford University Press, 2018

[18] Dubey K, Shah MT. Design and Simulation of Solar PV System. In: International Conference on Automatic Control and Dynamic Optimization Techniques (ICACDOT), International Institute of Information Technology, Pune, India, 2016. 